\title{
Loading Rate Effect on the Uniaxial Compressive Strength (UCS) Behavior of Cemented Paste Backfill (CPB)
}

\author{
Zhanguo Xiu ${ }^{1}$, Shuhong Wang ${ }^{1 凶}$, Yingchun $\mathrm{Ji}^{2}$, Feili Wang ${ }^{1 凶}$, Fengyu Ren ${ }^{1}$, Van-Tuan Nguyen ${ }^{1}$ \\ ${ }^{1}$ School of Resources and Civil Engineering, Northeastern University, China. \\ ${ }^{2}$ School of Science, Engineering \& Environment, University of Salford, UK.
}

Corresponding Author: wangshuhong@mail.neu.edu.cn \& wangfeili@126.com

\section{Highlights}

- The increase of loading rate has a strengthening effect on the UCS behavior of CPB

- DIC method can effectively evaluate the whole and local deformation of CPB

- Characteristics of axial deformation can be divided into two phases

- A preferred loading rate for laboratory tests in assessing UCS of CPB was given

- Micro-structural examinations are essential in understanding the UCS behaviors

\begin{abstract}
Underground mined-out areas and tailings are the two major harmful consequences from metal mining industry. Cemented Paste Backfill (CPB) method, refilling the tailings back to the underground mined-out areas, has been widely used worldwide. Clear understanding on the uniaxial compressive strength (UCS) behavior of the CPB is very important for the stability analysis of the backfill structure and the parameters optimization of backfill plan. However, the UCS tests can be markedly affected by the testing loading rate. And few papers reported the effect of different loading rates on the UCS of CPB. In this study, the UCS behavior of 14-day cured CPB samples are investigated using five different loading rates: $0.1,0.25,0.5,1,2$ $\mathrm{mm} / \mathrm{min}$. The digital image correlation (DIC) method and scanning electron microscope (SEM) analysis were also carried out to help clearly understand the different loading rates effect on the deformation behavior and failure surfaces. The findings show that, the increase of loading rate has a strengthening effect on the UCS. The correlation between the loading rates and the UCS is more in line with an exponential function when the loading rates are between 0.1 and $2 \mathrm{~mm} / \mathrm{min}$. During the loading process with different loading rates, the axial deformation characteristics of all the tested CPB samples can be divided into uniform and non-uniform phases. And the loading rates of 0.5 and $1 \mathrm{~mm} / \mathrm{min}$ resulted the smallest standard deviation for both the axial displacement and the axial strain observed from the three preset monitoring points. As the loading rate increased, the $\mathrm{Ca} / \mathrm{Si}$ parameter on the fracture surface of the samples also increased slightly. The findings of this research clearly demonstrated the behavior of UCS under different loading rates, and also provided a key research evidence in selecting appropriate loading rate in assessing USC of CPB sample for laboratory tests.
\end{abstract}

Keywords: Tailings; Cemented paste backfill (CPB); Loading rates; Uniaxial compressive strength (UCS); Digital image correlation (DIC) 


\section{Introduction}

At present, the exploitation of underground mineral resources is still one of the important economic activities of all countries in the world. For metal mines, traditional mining methods tend to focus more on the production of valuable ore. However, the destruction of the surrounding environment can be easily overlooked [1-3]. Wastes generated from the mining or mineral dressing process (such as tailings, waste rock, waste water, etc.) and void areas from underground mined-out are the two major hazards that endanger surrounding environment and people's lives [4,5]. As a backfill materials, the cemented paste backfill (CPB) belongs to the scope of cemented tailings backfill (CTB). Compared with $\mathrm{CTB}$, CPB improves the overall working performance of the slurry with low bleeding, segregation and precipitation. Since the first attempt of using the CPB method in Germany's Bad Grund Mine in 1970s [6], this method has been widely applied in various mines around the world as a key method in managing tailings and underground mined-out areas due to its economic and environment benefits [7-9].

The advantages of $\mathrm{CPB}$ method can be summarized as follows: $a$. effectively solving the problem of mining solid wastes piling up on the surface which can cause serious environmental damages; $b$. significantly improving the stability of the underground mined-out areas (cavities or voids), which can ensure the underground working safety; and $c$. increasing the recovery rate of valuable ores which brings economic benefits.

Generally, the CPB slurry is a heterogeneous mixture of binder, dewatered tailings and water [10,11]. The solid content of CPB slurry is between $70 \%$ and $85 \%$ by weight, and the binder content is between $3 \%$ and $7 \%$ by weight (more than $10 \%$ when higher strength is required at early stages) [12]. The CPB slurry is usually prepared on the surface and transported by gravity or pumping to the underground mined-out areas. Then, the backfilled CPB slurry in the underground mined-out areas gradually builds up strength and stability through its own hydration consolidation during the curing time. Due to the redistribution and effective transmission of concentrated stresses around the rock walls in the underground mined-out areas, the CPB structure with an appropriate strength can not only effectively support the slippage of the rock walls, but also greatly reduce the occurrence of rock bursts [13]. Therefore, the strength design of CPB structure has important implications for engineering applications of CPB in managing mined-out areas.

The strength design parameters (mainly referring to the uniaxial compressive strength, UCS) of the CPB structure used to guide practical applications are mainly obtained by laboratory tests. It is well known that the UCS obtained from the laboratory is greatly affected by test conditions (e.g., sample preparation methods, specimen size and loading rates, etc.) [11,14-17]. However, there are currently no clear testing standards to guide the determination of UCS for CPB samples. It is therefore important to consider the influence of the changes in testing conditions on the UCS of CPB.

Many previous studies have shown that different loading rates have significant effects on UCS tests for rock or concrete [1822]. Currently many existing laboratory based studies to test the UCS of CPB used a specific given loading rate, for example, loading rate in Chen et al.'s work is $0.2 \mathrm{~mm} / \mathrm{min}$ [23]; in Jiang et al.'s work is $0.5 \mathrm{~mm} / \mathrm{min}$ [24] and in Fall and Pokharel's 
work is $1 \mathrm{~mm} / \mathrm{min}$ [25]. However, few papers reported the effect of different loading rates on the UCS of CPB. For the definition of different loading strain rates, Liang et al. [18] reported that the loading strain rate limit of rocks is either static when the loading strain rate is $5 \times 10^{-4} \mathrm{~s}^{-1}$ or quasi-dynamic when the loading strain rate is between $5 \times 10^{-4} \mathrm{~s}^{-1}$ and $10^{2} \mathrm{~s}^{-1}$. Cao et al. [26] reported that the loading rates $(50 \mathrm{~N} / \mathrm{s}$ to $200 \mathrm{~N} / \mathrm{s})$ have significant impacts on the UCS of cemented tailings backfill (CTB), which is evident from the damages of each tested sample assessed by acoustic emission (AE). Li et al. [27] reported that the UCS of CTB increased significantly as the loading rate increased (from $2 \mathrm{~mm} / \mathrm{min}$ to $8 \mathrm{~mm} / \mathrm{min}$ ). Huang et al. [28] evaluated the UCS changes of CPB at high loading strain rate (from $350 \mathrm{~s}^{-1}$ to $750 \mathrm{~s}^{-1}$ ), and correlations between the UCS and the loading strain rates were established. Liu et al. [29] studied the behavior of deformation and fracture of CTB samples under different cement-to-tailings $(\mathrm{c} / \mathrm{t})$ ratio and loading conditions. A damage constitutive model was established by using the AE method.

This paper will focus on the effects of different loading rates on the UCS of CPB samples as well as their digital image correlation (DIC) characteristics. From existing studies, when the static UCS of CPB was tested in laboratory, the loading rates used have been generally less than $2 \mathrm{~mm} / \mathrm{min}$. Following the loading rates commonly used in the laboratory, a series of UCS tests were carried out on CPB samples. Understanding early strength gain of the CPB is of special importance for the opening of barricades, and thereby, reducing mining cycle time and increasing mining efficiency and production. Therefore, the curing time of 14 days was selected in this study. A total of five different loading rates: $0.1,0.25,0.5,1$ and $2 \mathrm{~mm} / \mathrm{min}$ were considered and the DIC monitoring equipment was used to evaluate the deformation characteristics. Moreover, the micro-structural evolution was assessed by the scanning electron microscopy (SEM) with energy dispersive spectrum (EDS) analysis. It is expected that this study may serve as a reference for the laboratory tests.

\section{Experimental methodology}

\subsection{Testing material selection and sample preparation}

\subsubsection{Tailings}

It is worth noting that the natural tailings contain abundant chemical components (e.g., sulphate, etc.) that can have complex effects on their mechanical properties [30-32]. Artificial tailings or silica tailings (with $99.8 \% \mathrm{SiO}_{2}$ ) can effectively reflect the key mechanical behaviors of natural tailings, and in the meanwhile, eliminating the interference of the complications caused by the natural chemical components. Also, these types of this artificial tailings were widely used in laboratory to exam the mechanical behavior of CPB $[25,33,34]$. The main chemical element of the silica tailings is shown in Table 1 . And the artificial tailings and its scanning electron microscope (SEM) images are provided in Fig. 1. 
(a)
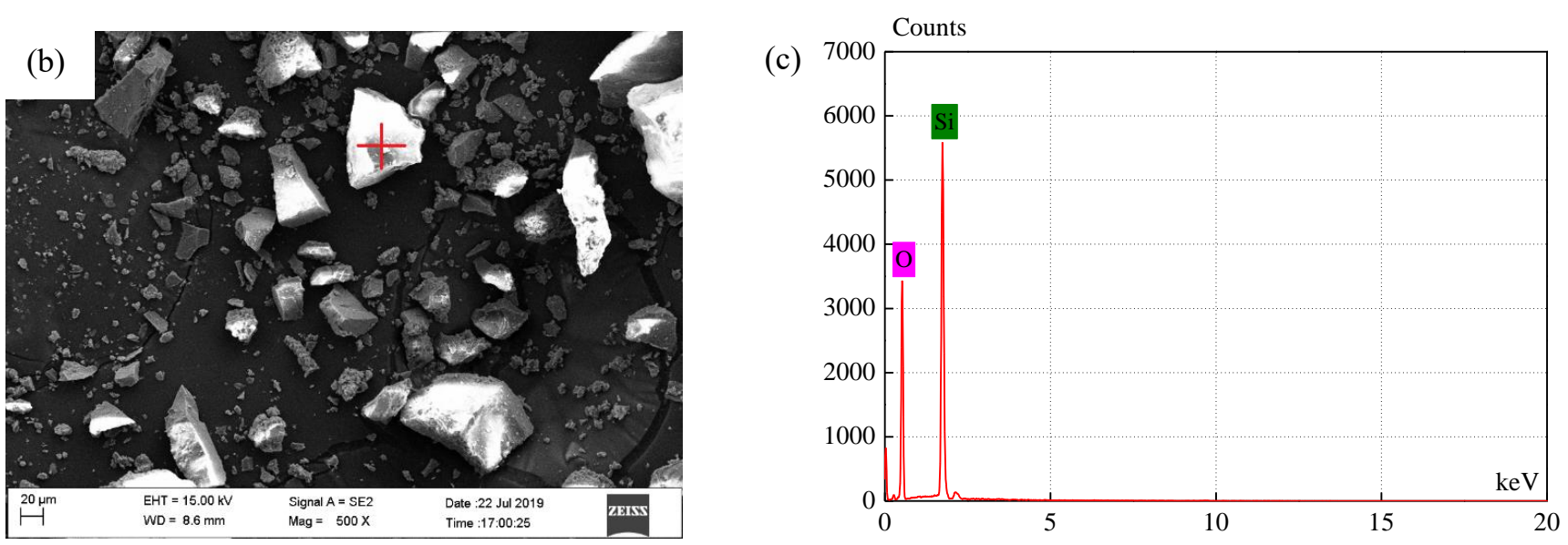

Fig. 1 The artificial tailings used in this study: (a) the artificial tailings used in this study; $(b)$ the scanning electron microscope (SEM) image (magnified 500 times); (c) the main elements of the artificial tailings

Table 1 Main chemical element of the silica tailings used.

\begin{tabular}{cccccccc}
\hline $\begin{array}{c}\text { Element } \\
\text { unit }\end{array}$ & $\begin{array}{c}\mathrm{Si} \\
\text { (wt.\%) }\end{array}$ & $\begin{array}{c}\mathrm{Al} \\
\text { (wt.\%) }\end{array}$ & $\begin{array}{c}\mathrm{Na} \\
(\text { wt.\%) }\end{array}$ & $\begin{array}{c}\mathrm{Fe} \\
\text { (wt.\%) }\end{array}$ & $\begin{array}{c}\mathrm{Pb} \\
\text { (wt.\%) }\end{array}$ & $\begin{array}{c}\mathrm{S} \\
\text { (wt.\%) }\end{array}$ & $\begin{array}{c}\mathrm{K} \\
\text { (wt.\%) }\end{array}$ \\
\hline Silica tailings & 99.80 & 0.10 & $<0.01$ & $<0.01$ & - & - & - \\
\hline
\end{tabular}

The particle sizes of silica tailings used in this study were assessed using a Mastersize 2000 laser particle size analyser (Malvern, $U K$ ). The particle size distribution of silica tailings is close to the average particle sizes of tailings from 7 mines randomly selected across different regions in China (Fig. 2). It can be seen from Fig. 2 that the fine particle contents (particle sizes are less than $20 \mu \mathrm{m}$ ) of the silica tailings and the average of 7 mines tailings are $39.07 \%$ and $41.96 \%$, respectively. According to the Unified Soil Classification System (USCS), these two types of tailings can be considered as fine-grained soils $[35,36]$. Table 2 shows the key physical properties of the two types of tailings. It can be seen from the test results that the particle size distributions of the two tailings are relatively close. Therefore, artificial tailings (silica tailings) are considered to be an alternative to natural tailings for the experimental research in this study. 


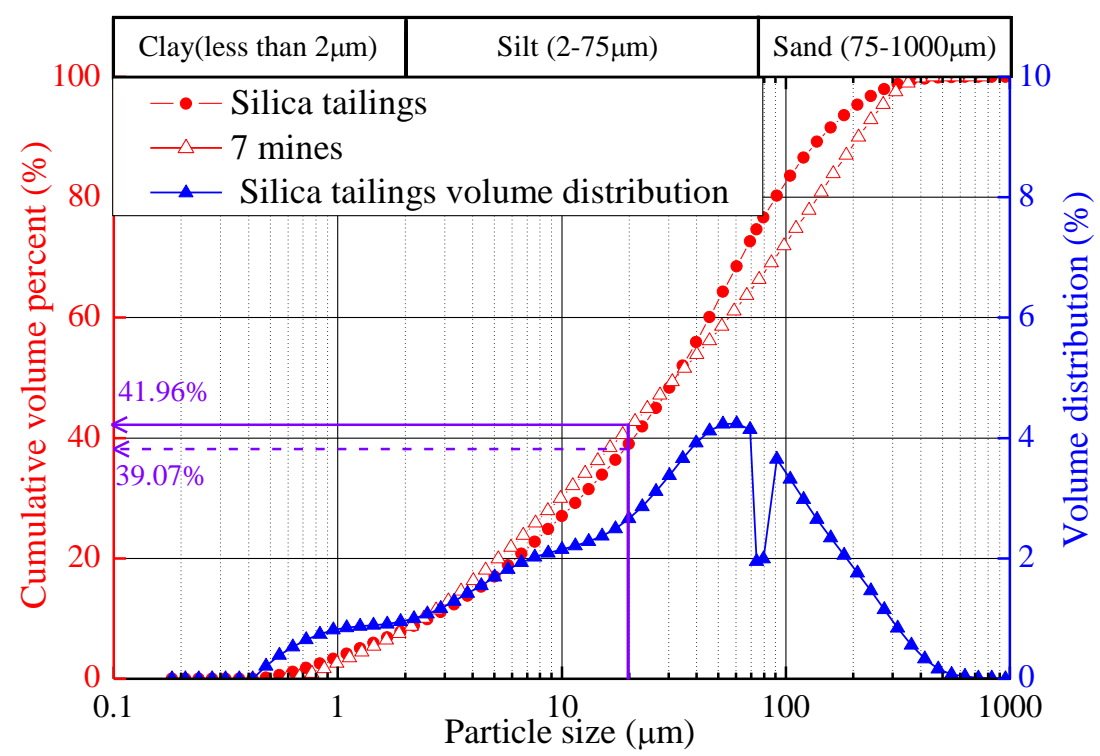

Fig. 2 The particle size distribution curves of the silica tailings and the average of 7 mines tailings

Table 2 Physical properties of the tailings.

\begin{tabular}{llll}
\hline Parameters & Unit & Silica tailings & 7 mine tailings \\
\hline$D_{10}$ (particle size at $10 \%$ passing) & $\mu \mathrm{m}$ & 2.550 & 2.413 \\
$D_{30}$ (particle size at 30\% passing) & $\mu \mathrm{m}$ & 12.064 & 9.860 \\
$D_{50}$ (particle size at $50 \%$ passing) & $\mu \mathrm{m}$ & 32.193 & 32.300 \\
$D_{60}$ (particle size at $60 \%$ passing) & $\mu \mathrm{m}$ & 45.609 & 55.804 \\
$D_{90}$ (particle size at $90 \%$ passing) & $\mu \mathrm{m}$ & 144.855 & 210.917 \\
$C_{\mathrm{u}}=D_{60} / D_{10}($ coefficient of uniformity) & - & 17.886 & 23.126 \\
$C_{\mathrm{c}}=\left(D_{30}\right) 2 /\left(D_{10} * D_{60}\right)($ coefficient of curvature) & - & 1.251 & 0.722 \\
$\Delta=\left(D_{90}-D_{10}\right) / D_{50}($ relative span factor) & - & 4.420 & 6.455 \\
Fines content $(<20 \mu \mathrm{m})$ & $\%$ & 39.070 & 41.960 \\
Classification & - & Fine-grained soil & Fine-grained soil \\
Shape of soil particle & - & Edges and corners & Edges and corners \\
\hline
\end{tabular}

\subsubsection{Binder}

Different types and content of binder have significant influences on the mechanical properties of CPB structure [37]. In this study, Ordinary Portland Cement (OPC), Type: P.O. 42.5, one of the most common types of binder, was used for preparing the CPB slurry. The main chemical composition of the used binder is shown in Table 3.

Table 3 Chemical composition of the studied binding agent (OPC, type: P.O.42.5).

\begin{tabular}{ccccccc}
\hline Varieties & $\begin{array}{c}\mathrm{CaO} \\
(\text { wt.\%) }\end{array}$ & $\begin{array}{c}\mathrm{SiO}_{2} \\
(\text { wt.\%) }\end{array}$ & $\begin{array}{c}\mathrm{Al}_{2} \mathrm{O}_{3} \\
(\text { wt.\%) }\end{array}$ & $\begin{array}{c}\mathrm{SO}_{3} \\
(\text { wt.\%) }\end{array}$ & $\begin{array}{c}\mathrm{MgO} \\
(\text { wt.\%) }\end{array}$ & $\begin{array}{c}\mathrm{Fe}_{2} \mathrm{O}_{3} \\
(\text { wt.\%) }\end{array}$ \\
\hline Content & 62.82 & 18.03 & 4.53 & 3.82 & 2.65 & 2.70 \\
\hline
\end{tabular}

\subsubsection{Mixing water}

In this study, the tap water was used to mix the binder and silica tailings. The chemical composition of tap water is shown in

Table 4.

Table 4 Chemical composition of tap water used as maxing water.

\begin{tabular}{cccccccc}
\hline Varieties & $\begin{array}{c}\text { Conductivity } \\
(\mu \mathrm{S} / \mathrm{cm})\end{array}$ & $\begin{array}{c}\mathrm{pH} \\
(-)\end{array}$ & $\begin{array}{c}\text { Chloride } \\
(\mathrm{mg} / \mathrm{L})\end{array}$ & $\begin{array}{c}\text { Aluminum } \\
(\mu \mathrm{g} / \mathrm{L})\end{array}$ & $\begin{array}{c}\text { Sulfate } \\
(\mathrm{mg} / \mathrm{L})\end{array}$ & $\begin{array}{c}\text { Sodium } \\
(\mathrm{mg} / \mathrm{L})\end{array}$ & $\begin{array}{c}\text { Iron } \\
(\mu \mathrm{g} / \mathrm{L})\end{array}$ \\
\hline Content & 87.7 & 7.59 & 8.47 & 2.30 & 3.75 & 4.18 & 0.92 \\
\hline
\end{tabular}




\subsubsection{Sample preparation}

CPB slurry was prepared by mixing the dewatered tailings, Ordinary Portland Cement (P.O. 42.5) and tap water within a mortar mixer. The mixture was stirred about 10 minutes to obtain a homogeneous paste. The slurry were prepared with a solid content of $75 \mathrm{wt} . \%$, and the water-to-binder ratio (w/c) and binder content of CPB samples were held at 4.75 and 7.55 wt.\%, respectively. The slump of the fresh paste mixture, measured by using a slump test in accordance with ASTM C143/C143M15 [38], is more than $18 \mathrm{~cm}$, which is a slump value mostly used in many backfilling operations. After the mixing process, the homogeneous slurry was then filled into plastic molds with a diameter of $50 \mathrm{~mm}$ and a height of $100 \mathrm{~mm}$. To prevent the loss of moisture during the curing, all $\mathrm{CPB}$ samples were sealed. Then, the prepared samples were placed in an environmentally controlled chamber to maintain temperature at $20 \pm 2^{\circ} \mathrm{C}$ and relative humidity $90 \pm 5 \%$ curing for 14 days.

\subsection{Experimental apparatus and testing procedure}

\subsubsection{Experimental apparatus}

UCS loading System: To accurately obtain the UCS parameters of the CPB samples under different loading rates, the GCTS (Geotechnical Consulting \& Testing System, BST Instruments Limited Co., China) testing system was used to test the UCS behavior, as shown in Fig. 3. The displacement control loading was used in the UCS tests. A total of five different loading rates were set to $0.1,0.25,0.5,1$, and $2 \mathrm{~mm} / \mathrm{min}$, these rates belong to the category of static loading and often used in the laboratory tests. The stress and displacement data of each tested sample were recorded by a data collection system during the whole loading process. It should be noted that before the start of each test, the loading system applies a stress of $5 \mathrm{kPa}$ to the tested sample, which ensures that the loading bar can be in close contact with the tested sample.

Digital Image Correlation (DIC) System: As an optical technique, the DIC method is established by the vision technology and digital image technology. The spatial shape, full-field displacement and strain data of the tested samples were provided using the image correlation algorithms. The DIC technique can trace the motion state of each point (speckle) on the surface of the tested samples during the testing process. And the deformation of the whole tested samples can be obtained by comparing and analyzing the speckle characteristic randomly distributed on the surface before and after a loading. This technology is also called digital speckle correlation method (DSCM). For the detailed calculation principles of the DIC method, the readers can refer to the Refs [39-41].

The DIC method was used for each tested sample mentioned in this paper. And due to the tested sample is a cylinder shape, two cameras are used for the measurement. The DIC testing system with two cameras has been used extensively for nonplanar samples in the past [42,43]. Fig. 3 shows the experimental set-up for DIC equipment (Type: $3 D$ full-field strain measurement and analysis system, XTOP 3D Technology Co. Ltd. China). As shown in Fig. 3, the two cameras and light sources were mounted on a tripod in front of the tested sample and they were used to get an adequate image contrast. Fig. 4 is a simplified schematic diagram of DIC method. In each testing process, it should be noted that the loading system works 
simultaneously with the DIC system, and two different systems obtain their corresponding data independently.

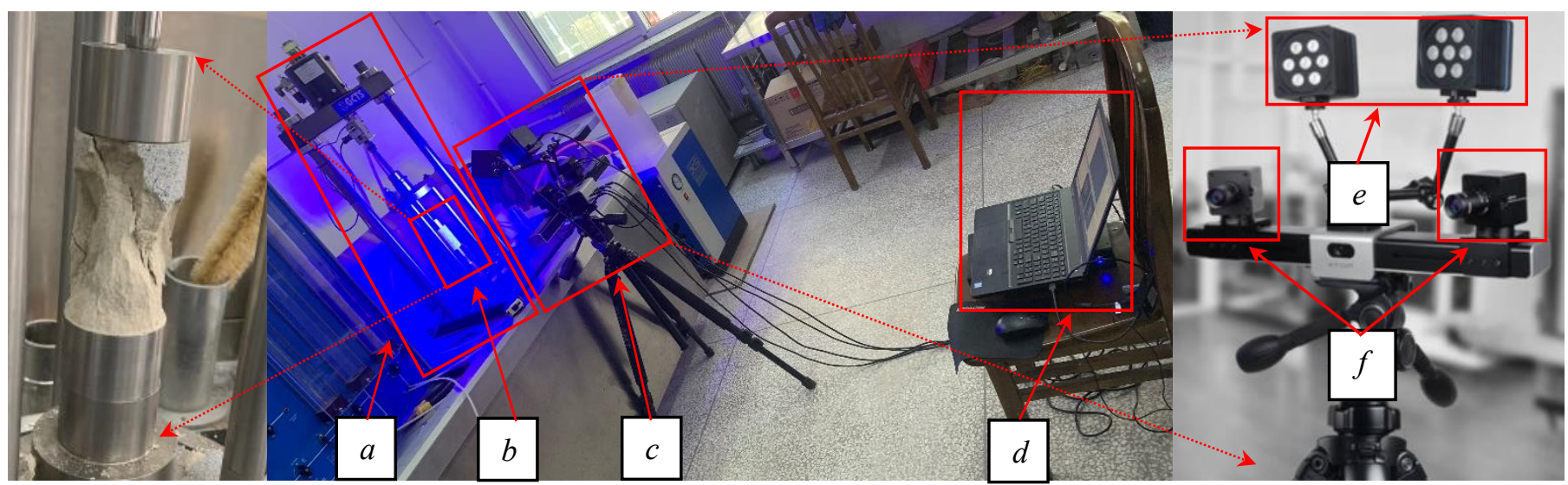

Fig. 3 Experimental set-up for DIC system: $a$. Loading system; $b$. Tested sample; $c$. DIC apparatus; $d$. DIC computer; $e$.

Light sources; $f$. Cameras

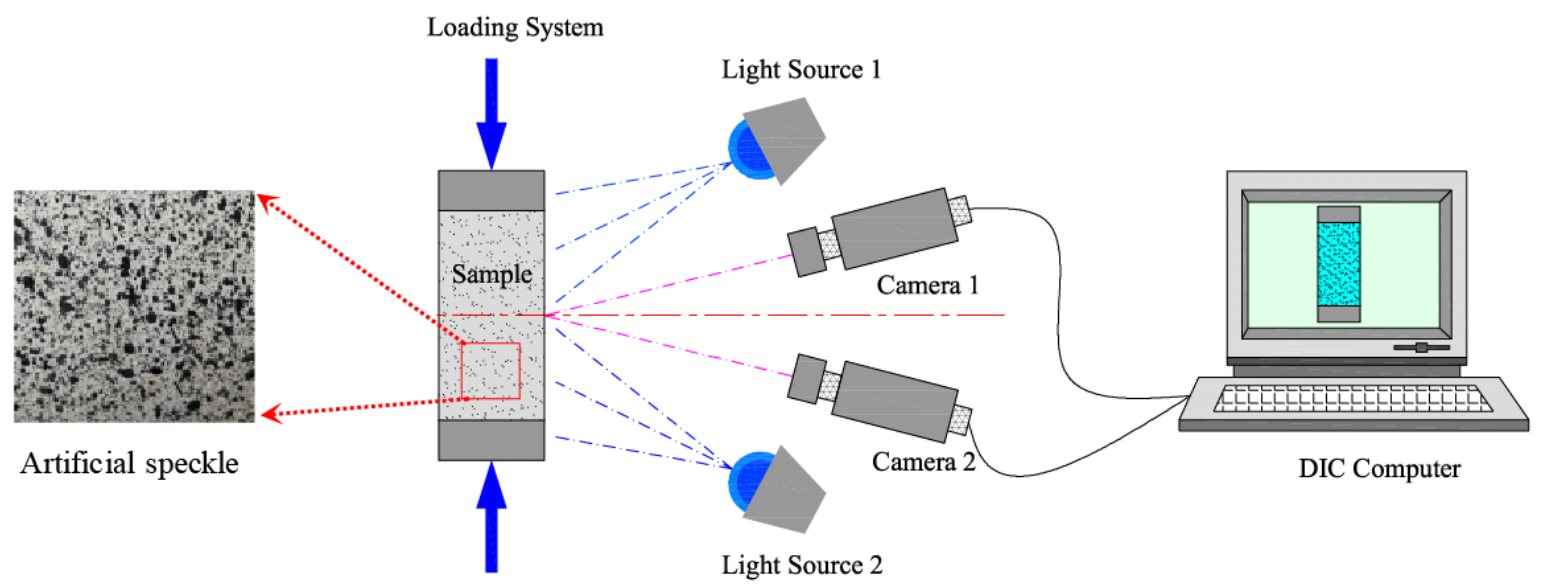

Fig. 4 The simplified schematic diagram of DIC method

The application of the DIC testing system involves four main steps: $a$. the artificial speckle with black and white matte spray lacquer was made on the surface of completed samples. $b$. the DIC apparatus was fixed and the position and auxiliary lighting were adjusted according to the testing conditions. $c$. the region of interest (ROI, the region of blue grid, as shown in Fig. 5) on the surface of each tested sample and the calculation parameters of the DIC software (e.g. subset size, step size, etc.) were selected. $d$. the full-field or each-point displacement and strain of the ROI for each tested sample were calculated and saved on the computer. It also should be noted that the points $1^{\#}, 2^{\#}$ and $3^{\#}$ shown in Fig. 5 are three monitoring points.

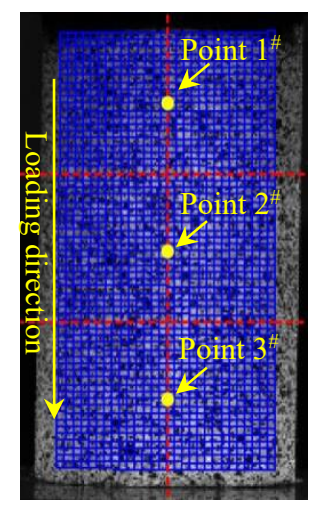

Fig. 5 The region of interest (ROI) of a tested sample

Scanning Electron Microscope (SEM) analysis: The micro-structure of CPB has a great influence on its own UCS. To study 
the micro-structure of CPB, the scanning electron microscopy (SEM) with energy dispersive spectrum (EDS) analysis is often used. SEM with EDS is an effective tool in examining evidence of how changes in micro-structures can cause change in material physical properties, in the current study, the changes of UCS. A small portion will be separated from the failure surface of the tested samples. Then, the separated small samples will be dried and gilded for observation under the SEM device. In this paper, a scanning electron microscopy with energy dispersive X-ray spectroscopy (Type:Ultra Plus, Zeiss, Germany) was used to study the micro-structure of CPB. This SEM-EDS tool is used not only to observe the microscopic morphology of the fracture surface, but also to analyse the chemical elements on the designated area of the failure surface. This method will facilitate the identification and analysis of hydration products on the failure surface.

\subsubsection{Testing procedure}

After 14 days of curing time, the hardened CPB samples were extracted from the plastic molds. In order to determine their mechanical strength properties, all the samples were subjected to UCS tests with a digital image correlation (DIC) method. Five loading rates $(0.1 \mathrm{~mm} / \mathrm{min}, 0.25 \mathrm{~mm} / \mathrm{min}, 0.5 \mathrm{~mm} / \mathrm{min}, 1 \mathrm{~mm} / \mathrm{min}$ and $2 \mathrm{~mm} / \mathrm{min})$ were considered based on the most common loading rates used in laboratory tests. And the total displacement is $5 \mathrm{~mm}$ for each tested CPB sample. The detailed UCS testing parameters of CPB samples are shown in Table 5. The difference of CPB in height (second column) was caused by the volume shrinkage during the hydration and consolidation process. And it is assumed the small changes (between $0.5 \mathrm{~mm}$ to $1.1 \mathrm{~mm}$ ) in height will not have a significant effect on the testing results. Also, the sample ID named with "M-14-0.1" refers to a sample with curing time of 14 days, and loading rate of $0.1 \mathrm{~mm} / \mathrm{min}$, as shown in the table.

Table 5 The UCS test parameters of CPB samples subjected to different loading rates.

\begin{tabular}{ccccccc}
\hline Sample ID & $\begin{array}{c}\text { Height } \\
(\mathrm{mm})\end{array}$ & $\begin{array}{c}\text { Loading rate } \\
(\mathrm{mm} / \mathrm{min})\end{array}$ & $\begin{array}{c}\text { Curing time } \\
(\text { days })\end{array}$ & $\begin{array}{c}\text { Solid content, } \\
C_{\mathrm{wt} . \%}(\%)\end{array}$ & w/c ratio & $\begin{array}{c}\text { Binder content, } \\
B_{\text {wt.\% }}(\%)\end{array}$ \\
\hline M-14-0.1 & 99.5 & 0.1 & 14 & 75 & 4.75 & 7.55 \\
M-14-0.25 & 99.1 & 0.25 & 14 & 75 & 4.75 & 7.55 \\
M-14-0.5 & 98.9 & 0.5 & 14 & 75 & 4.75 & 7.55 \\
M-14-1 & 99.5 & 1 & 14 & 75 & 4.75 & 7.55 \\
M-14-2 & 99.3 & 2 & 14 & 75 & 4.75 & 7.55 \\
\hline
\end{tabular}

Note: $B_{\mathrm{wt} \%}=100^{*} M_{\mathrm{binder}} / M_{\text {dry-tailings }} ; C_{\mathrm{wt} \%}=100^{*} M_{\text {soild }} / M_{\text {total. }}$. Where, $M_{\text {binder }}$ is the mass of binder; $M_{\text {dry-tailings }}$ is the mass of dry tailigs; $M_{\text {soild }}$ is the mass of dry solids (binder + tailings) and $M_{\text {total }}$ is the total mass of CPB (binder + tailings + water).

\section{Results of UCS testing}

\subsection{The UCS characteristics of the CPB samples}

For all the CPB samples, conventional UCS tests were performed following the testing procedure given in Table 5, and their corresponding UCS values under different loading rates were measured. It should be noted that the testing program was executed by the loading system, and the testing results were saved by an independent data acquisition system.

The typical Axial stress vs. Axial displacement curves of the same CPB samples under different loading rates were shown in Fig. 6. As can be seen from Fig. 6, the tested CPB samples exhibited different UCS (represented by the maximum axial stress) 
values under different loading rates. This indicates that the loading rates have an important impact on the UCS values. Besides the differences in UCS values under different loading rates, all the Axial stress $v s$. Axial displacement curves show a similar trend, with an increase up to the peak stress value, and then, followed by a decrease to the end of test. It also can be seen from Fig.6 that the axial displacement required for each tested sample to the peak stress value is reduced when the loading rate increases from $0.1 \mathrm{~mm} / \mathrm{min}$ to $0.5 \mathrm{~mm} / \mathrm{min}$. When the loading rate is $2 \mathrm{~mm} / \mathrm{min}$, the required axial displacement for reaching the peak stress is $1.9843 \mathrm{~mm}$, which is very close to the $1.9788 \mathrm{~mm}$ for $0.5 \mathrm{~mm} / \mathrm{min}$ and $1.8655 \mathrm{~mm}$ for $1 \mathrm{~mm} / \mathrm{min}$. This observation indicates that when the loading rate is between 0.5 and $2 \mathrm{~mm} / \mathrm{min}$, the axial displacement required for reaching the peak stress is similar (small variations). However, when the loading rate is between 0.1 and $0.5 \mathrm{~mm} / \mathrm{min}$, the corresponding axial displacements have a much bigger variation as the loading rate increases (reduced from $3.0754 \mathrm{~mm}$ to $1.9788 \mathrm{~mm}$ ). Due to fast accumulated energy cannot be released at the same speed under different loading rates, the deformability of the whole sample was decreased as the loading rate increased (from 0.1 to $0.5 \mathrm{~mm} / \mathrm{min}$ ). Therefore, the maximum displacement required to reach the peak stress is gradually decreasing when the loading rate is increased.

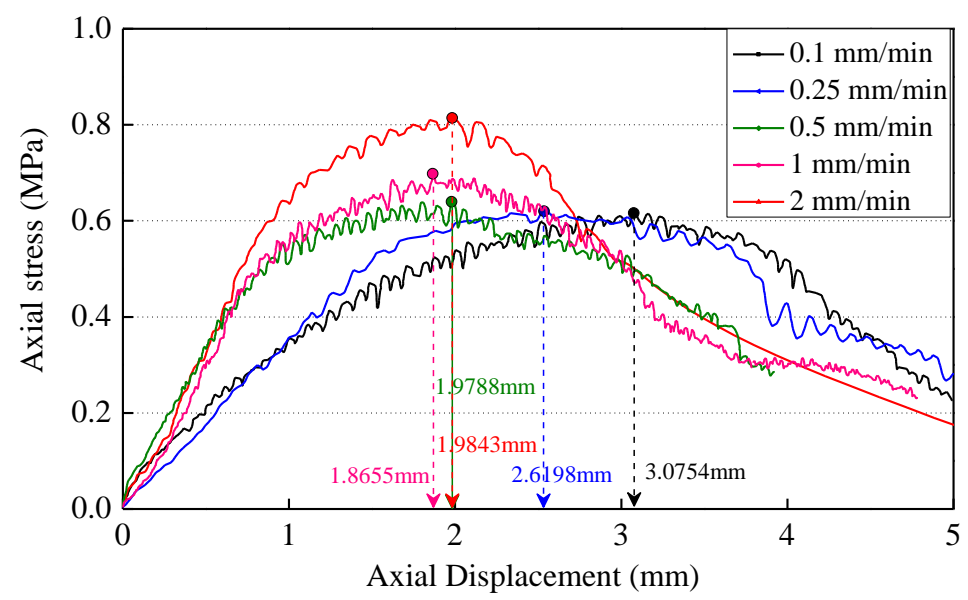

Fig. 6 The Axial stress vs. Axial displacement curves under different loading rates

To further investigate the effect of loading rates on UCS, the correlations between UCS and loading rates were plotted in Fig. 7. As the loading rate increases, the UCS gradually increases. The UCS is $0.6160 \mathrm{MPa}$ at a loading rate of $0.1 \mathrm{~mm} / \mathrm{min}$, while the loading rate is increased to $2 \mathrm{~mm} / \mathrm{min}$ the UCS of the same sample reaches to $0.8138 \mathrm{MPa}$, an increase of $32.11 \%$. With the tested loading rates, i.e., from 0.1 to $0.25 \mathrm{~mm} / \mathrm{min}, 0.25$ to $0.5 \mathrm{~mm} / \mathrm{min}, 0.5$ to $1 \mathrm{~mm} / \mathrm{min}$ and 1 to $2 \mathrm{~mm} / \mathrm{min}$, the UCS values are increased by $0.62 \%, 2.00 \%, 9.07 \%$ and $16.62 \%$, respectively. The results also show that the loading rate has a strengthening effect on the UCS of CPB. There are the various reasons contributing the strengthening effect. When the loading rate increases, the time required for the material responding to the strain is reduced, which will make the strain more localized, so that the overall sample will need more stress to break. Moreover, the development of micro-cracks inside the sample is greatly restricted as the loading rate increased, which makes the force-bearing area of the sample increased, thereby increasing the strength of the sample.

In addition, to establish a suitable mathematical formula to describe the relationship between the loading rate and the UCS of 
the tested CPB samples, a few curve fitting methods (e.g., linear, polynomial, exponential and logarithmic, etc.) were performed using the tested results. Among those curve fitting methods tested, only the polynomial and exponential fitting functions resulted higher multiple correlation coefficients $\left(\mathrm{R}^{2}\right.$, greater than 0.95$)$. The two fitting lines are shown in Fig. 7 and their mathematical formula are shown in Table 6 . Based on the fitting results, when the loading rate is range from $0.1 \mathrm{~mm} / \mathrm{min}$ to $2 \mathrm{~mm} / \mathrm{min}$, the increase of UCS against the increase of loading rates follows an exponential function, which can provide a reference for predicting the UCS of the CPB sample.

Table 6 The fitting results of relationship between the peak UCS and loading rate

\begin{tabular}{ccc}
\hline \multirow{2}{*}{ Parameters } & \multicolumn{2}{c}{ Fitting methods } \\
\cline { 2 - 3 } & $y=0.6665-0.065 x+0.0188 x^{2}$ & $y=0.6060+0.0929 \mathrm{e}^{0.0712 x}$ \\
Fitting formula & 0.9874 & 0.9970 \\
\hline
\end{tabular}

Note: $y$ and $x$ refer to the UCS and loading rate, respectively.

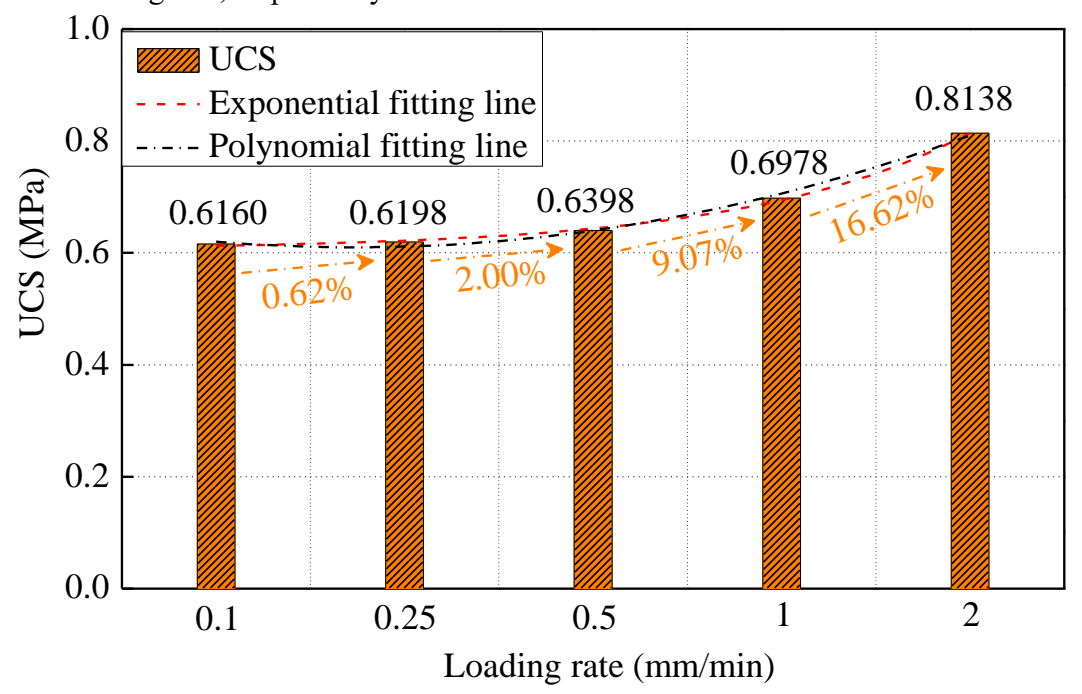

Fig.7 The relationship between UCS and loading rate for tested CPB samples

\subsection{Analysis of the DIC results}

Since the DIC method can well record the strain and displacement of the tested sample during the whole loading process, it is therefore hoped the DIC method will be able to explain the failure process of the tested sample. In the recorded testing results, the stress concentration position of the tested samples can be reflected from their strain testing results. Similarly, the development of strain concentration can also reflect the process of crack development. Table 7 shows the axial strain results of DIC tests for CPB samples under different loading rates. Regardless of various loading rates, the DIC strain testing results show that the overall strain of each tested sample is non-uniform, and there is an obvious strain concentration zone (SCZ), and this SCZ changes continuously with the loading process.

In Table 7, the red arrow represents the development direction of strain concentration. From the testing results, it is evident that the CPB's failure process is different under different loading rates. When the loading rate is at the lower end $(0.1 \mathrm{~mm} / \mathrm{min})$, the micro-cracks of the tested sample can be fully expanded during the loading process, and the tested sample has sufficient time for stress redistribution, the accumulated energy can be fully released. With the progress of the loading process, the tested 
sample was broken along a main crack, and the secondary crack developed around the main crack. When the loading rate increases to 0.25 and $0.50 \mathrm{~mm} / \mathrm{min}$, the $\mathrm{SCZ}$ of each tested sample gradually develops from the top to the bottom of the samples. These tested results show that the micro-cracks inside the samples can continue to develop as the loading process continues. The development of micro-cracks is multi-directional and not unique. With the increase of the loading rate, the energy accumulated inside the sample cannot be effectively released, and the energy tends to accumulate in certain part of the tested sample $(1 \mathrm{~mm} / \mathrm{min}$ : accumulates at the bottom of the tested sample, $2 \mathrm{~mm} / \mathrm{min}$ : accumulates at the top of the tested sample). The tested sample was damaged by the suddenly released of the accumulated energy at a local position. Also, since the higher loading rate can lead to a rapid accumulation of a large amount of energy, the UCS values of the tested samples will be increased.

Table 7 The axial strain results of DIC tests for CPB samples under different loading rates

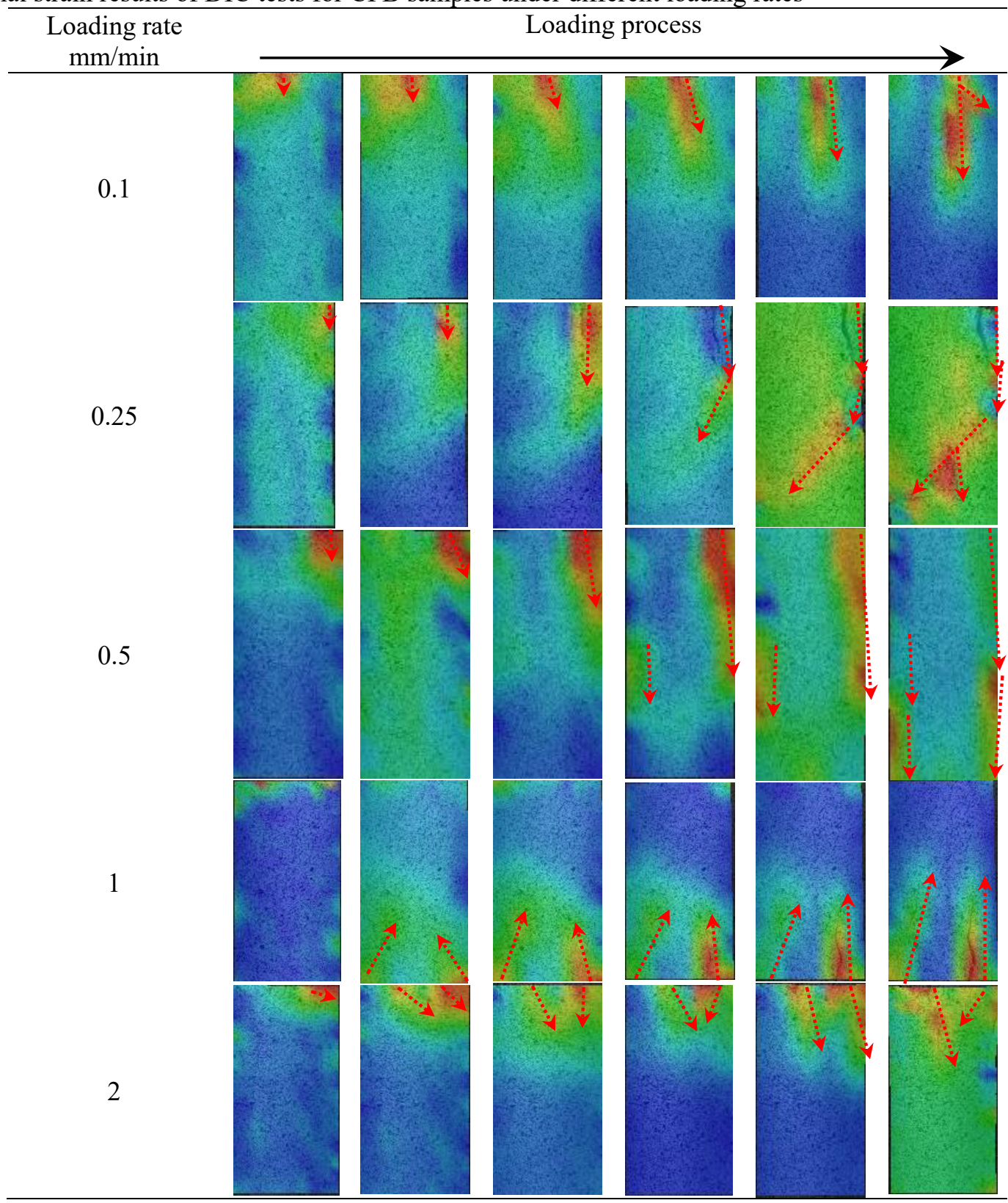

It can be known from Table 7 that when the loading rate is $2 \mathrm{~mm} / \mathrm{min}$, the length of the crack development is significantly less than $1 \mathrm{~mm} / \mathrm{min}$, which indicates that a higher loading rate can cause more energy accumulation and the energy cannot be 
released in time. In addition, when the energy is accumulated to a critical level, the energy is released instantaneously (similar to a rock burst), and the tested sample shows an obvious brittle failure. For example, when the loading rate is $2 \mathrm{~mm} / \mathrm{min}$, the stress decreases linearly after the Axial stress $v s$. Axial displacement curve reaches its peak stress (as shown in Fig. 6).

To further study the deformation characteristics of CPB samples under different loading rates, the axial displacement and axial strain data of the three preset monitoring points on the sample surface were extracted and analyzed. As shown in Fig. 5, the ROI is divided into three equal parts along the loading direction, and the three preset monitoring points were located at the center of each part. Fig. 8 shows the axial displacement and axial stain curves of the three points for the tested CPB samples under different loading rates. It should be noted that the name of the abscissa ( $x$-axis) in Fig. 8 is state ID. The values of state ID here is related to the acquisition interval of the DIC data acquisition system. In this study, for testing samples with a lower loading rate, the corresponding time interval for DIC data acquisition is larger. In contrast, a smaller time interval for DIC data acquisition was used with a larger loading rate. Therefore, the same state ID value at different loading rates does not necessarily represent the same time interval for DIC acquisition.
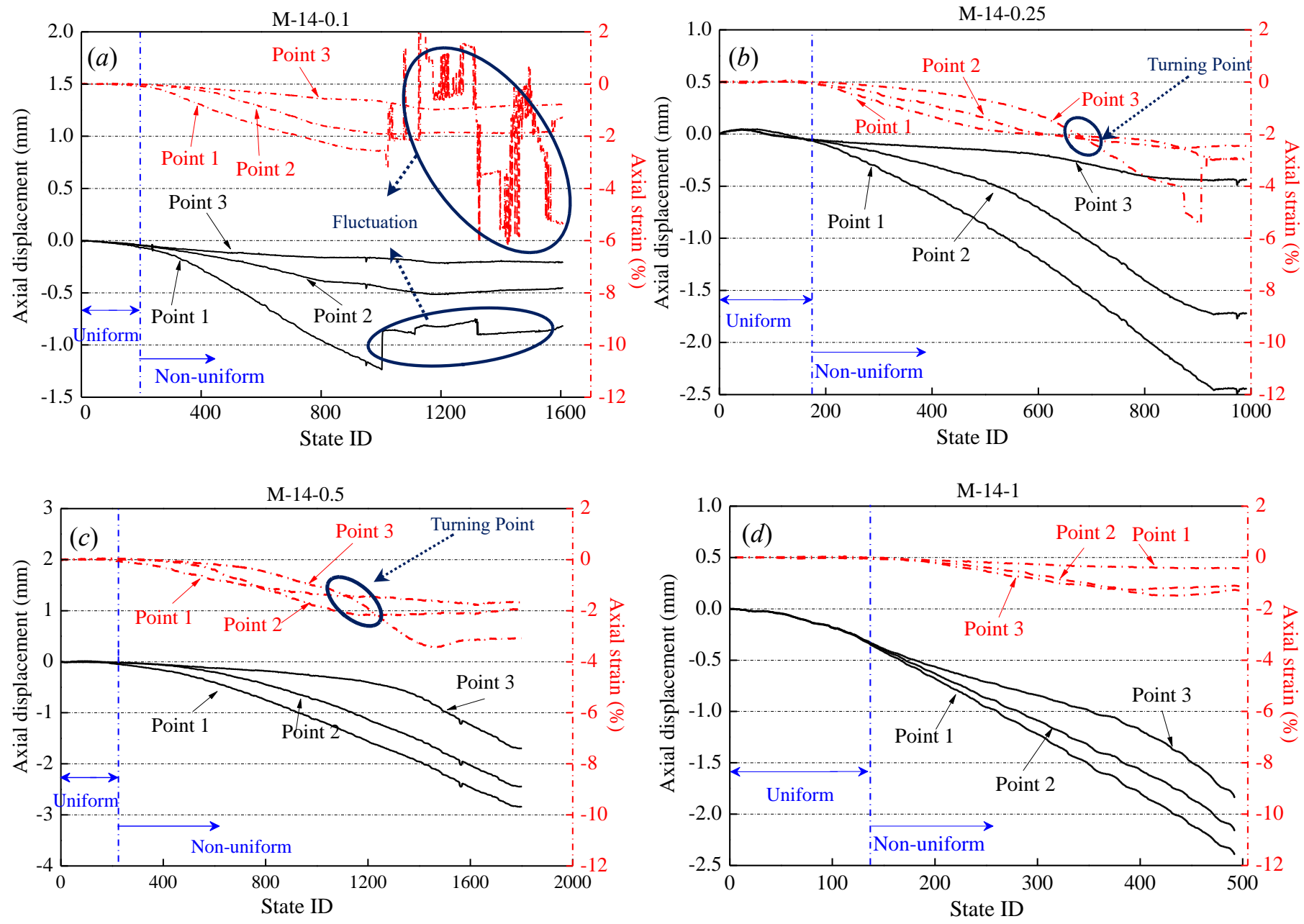


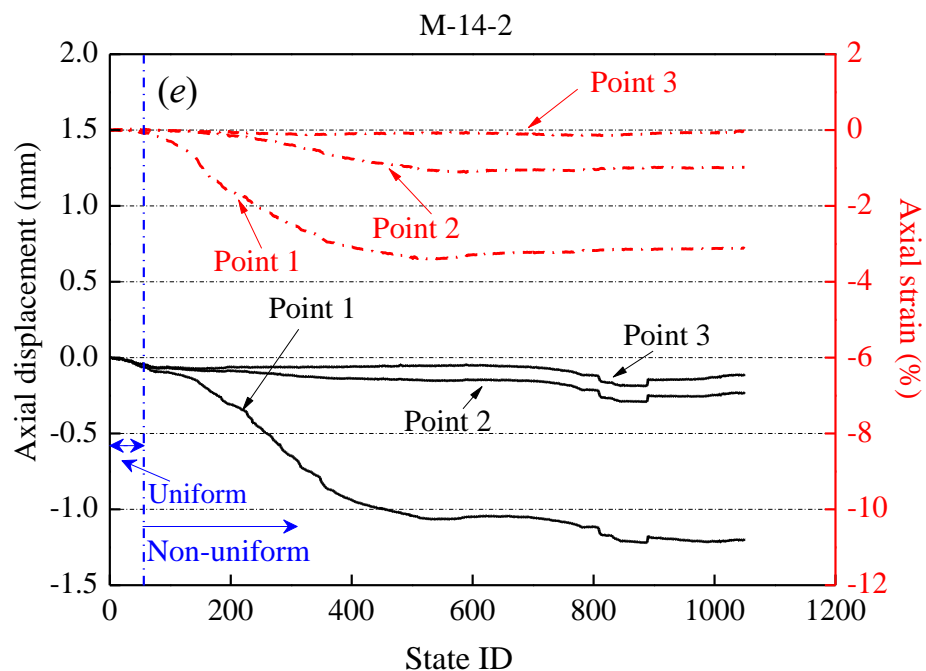

Fig. 8 The axial displacement and axial stain curves for the given three points of the tested CPB samples: (a) $0.1 \mathrm{~mm} / \mathrm{min}$; (b) $0.25 \mathrm{~mm} / \mathrm{min}$; (c) $0.5 \mathrm{~mm} / \mathrm{min}$; (d) $1 \mathrm{~mm} / \mathrm{min}$; (e) $2 \mathrm{~mm} / \mathrm{min}$

For each tested sample, the axial deformation (displacement or strain) from the preset three monitoring points distributed at different positions on the ROI surface (ref: Fig. 5) with the same state ID value can reflect the uniformity of deformation along the loading direction. When the difference in axial strain or axial displacement of the three monitoring points is large, it means that the corresponding deformation of the sample is non-uniform. It can be seen from the test results in Fig. 8 that, regardless of the change in the loading rates, at the initial stage of loading, the axial displacement values of the three monitoring points are at a relative same level, which indicates that the axial displacement of the whole sample is changed uniformly during the initial loading process. As the loading continued, the axial displacement of each monitoring point showed significant differences. The displacement at $1^{\#}$ point is significantly larger than the other two points $\left(2^{\#}\right.$ and $\left.3^{\#}\right)$, and the axial displacement clearly showed a non-uniform trend. The axial displacement of the whole sample was changed from uniform to non-uniform, Fig. 8 clearly shows the two stages of change for all the loading rates.

However, for the changes of axial strain, it shows a different trend compared with the axial displacement under different loading rates. Similarly, in the initial stage of loading, the axial strains of the three monitoring points are at the relative same level, and the strain values are smaller. Therefore, the sample experienced uniform change in axial strain. As the loading continued, the axial strain of the tested samples changed nonuniformly. This is due to the presence of SCZ, which has a large axial strain value. The location and development trend of the axial SCZ are different under different loading rates (as shown in Table 7). The change of SCZ reflects the cracks development process of the tested samples under different loading rates. It can be seen from Table 7 that when the loading rates are 0.25 and $0.5 \mathrm{~mm} / \mathrm{min}$, the $\mathrm{SCZ}$ of tested samples develop from the top to the bottom. Therefore, the obvious turning point of axial strain can be reflected in Fig. $8(b)$ and $(c)$. In addition, when the loading rate is $1 \mathrm{~mm} / \mathrm{min}$, the SCZ occurs at the bottom of the tested sample. Therefore, the axial strain at point $3^{\#}$ in Fig. $8(d)$ is greater than the other two points $\left(1^{\#}\right.$ and $\left.2^{\#}\right)$. It should be noted that when the loading rate is $0.1 \mathrm{~mm} / \mathrm{min}$, the obvious fluctuation of the axial strain and displacement curves for the monitoring point $1^{\#}$ in the later stage of loading are caused by 
the crack passing through the monitoring point $1^{\#}$.

To study the axial deformation of the CPB sample when it reaches the UCS, Table 8 shows the axial displacement and axial strain values at the preset three monitoring points (ref: Fig. 5) when each sample reaches the UCS under different loading rates.

Table 8 The displacement and axial strain of CPB samples at the peak USC for each given three points under different loading rate.

\begin{tabular}{|c|c|c|c|c|c|c|c|c|}
\hline \multirow[b]{2}{*}{$\begin{array}{l}\text { Sample } \\
\text { ID }\end{array}$} & \multirow[b]{2}{*}{$\begin{array}{l}\text { Peak stress } \\
\quad / \mathrm{MPa}\end{array}$} & \multirow[b]{2}{*}{$\begin{array}{l}\text { Corresponding } \\
\text { displacement } \\
\quad / \mathrm{mm}\end{array}$} & \multicolumn{2}{|c|}{ Point $1^{\#}$} & \multicolumn{2}{|c|}{ Point $2^{\#}$} & \multicolumn{2}{|c|}{ Point $3^{\#}$} \\
\hline & & & $\begin{array}{c}\text { Axial } \\
\text { displacement } \\
/ \mathrm{mm}\end{array}$ & $\begin{array}{l}\text { Axial } \\
\text { strain } \\
/ \%\end{array}$ & $\begin{array}{c}\text { Axial } \\
\text { displacement } \\
/ \mathrm{mm}\end{array}$ & $\begin{array}{l}\text { Axial } \\
\text { strain } \\
/ \%\end{array}$ & $\begin{array}{c}\text { Axial } \\
\text { displacement } \\
/ \mathrm{mm}\end{array}$ & $\begin{array}{l}\text { Axial } \\
\text { strain } \\
\quad / \%\end{array}$ \\
\hline M-14-0.1 & 0.6160 & 3 & -1.2359 & -2.5530 & -0.4462 & -1.91 & -0.1685 & -0.6758 \\
\hline M-14-0.25 & & & 4 & & -0.5 & $-1 .(6)$ & -0.1676 & -0.8340 \\
\hline M-14 & & & & -0.9 & -0.3 & -0. & -0.1 & -0.2980 \\
\hline M-14-1 & 0 & 1.8 & -1.2514 & -0.28 & -1.1121 & -0.7390 & -0.8581 & -0.9134 \\
\hline M-14-2 & 0.8138 & 1.9834 & -0.9664 & -3.1560 & -0.1388 & -0.8133 & -0.0587 & -0.0943 \\
\hline
\end{tabular}

It can be known from the data in Table 8 that when the tested sample reaches the UCS, the axial strain and the axial displacement values of the three monitoring points for each sample are different. This observation indicates that, when the samples reached their UCS under different loading rates, the tested samples are in a non-uniform deformation state. Normally, the standard deviation of a data set can objectively and accurately reflect the degree of dispersion for that particular set of data. Fig. 9 shows the standard deviations of the axial displacement and axial strain at the three monitoring points of the tested samples under different loading rates. The smaller the standard deviation of the sample, the more uniform the axial displacement and the axial strain of the tested sample. In this paper, the formula for calculating the standard deviation followed as:

$$
\sigma(r)=\sqrt{\frac{1}{N} \sum_{i=1}^{N}\left(x_{i}-r\right)^{2}}
$$

Where, $\sigma(r)$ is the standard deviation; $N$ is the number of monitoring points $(N=3) ; i$ is the monitoring point $(i=1,2$ and 3$)$;

$x_{i}$ is the value of the each monitoring point; $r$ is the average of the monitoring values for the three points.
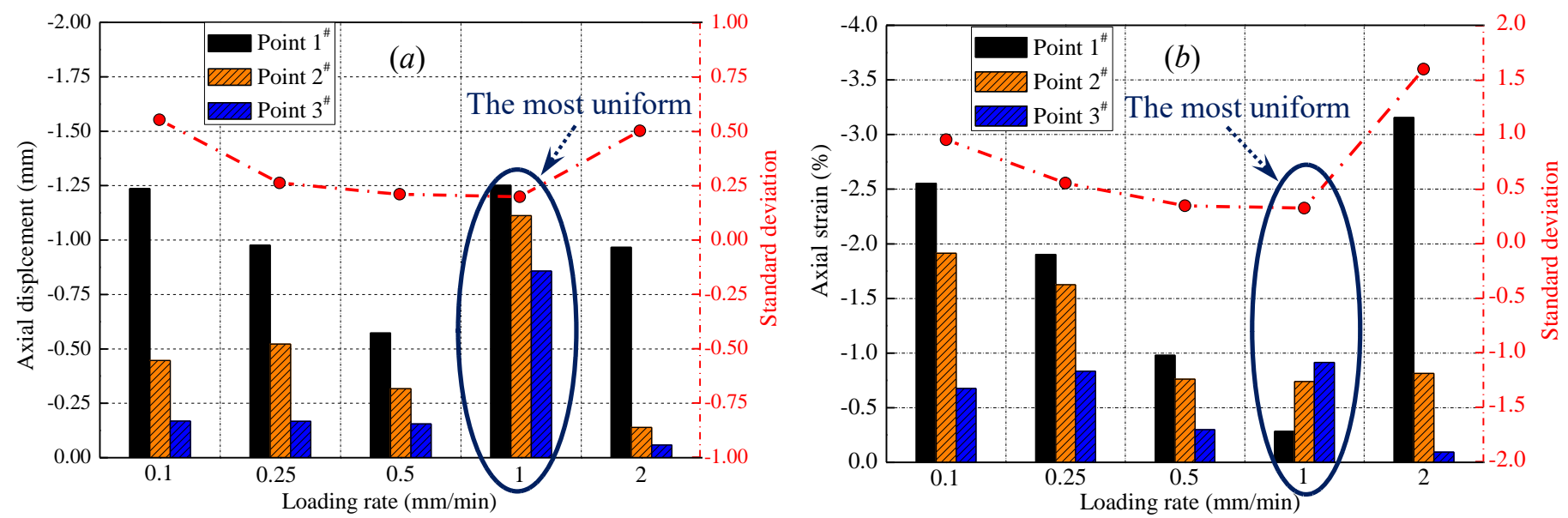

Fig. 9 The standard deviations of displacement and axial strain at the USC under different loading rates: $(a)$ axial displacement; $(b)$ axial strain 
It can be known from Fig. 9(a) that, regardless of the loading rates, the axial displacements of the tested CPB samples show that the displacement at monitoring point $1^{\#}$ is greater than that of point $2^{\#}$, and the smallest displacement is at point $3^{\#}$. As the loading rate increases, the standard deviation results on Fig. 9(a) show a trend of decreasing first and then increasing. When the loading rate is $1 \mathrm{~mm} / \mathrm{min}$, the axial displacement values at the preset three monitoring points for the tested samples are the largest, but the standard deviation is the smallest. This shows that, when the loading rate is $1 \mathrm{~mm} / \mathrm{min}$, the axial displacement of the whole tested sample is of the most uniformity among the 5 loading rates, and followed by $0.5 \mathrm{~mm} / \mathrm{min}$. In addition, it can be seen from Fig. 9(b) that, for the axial strains under different loading rates, the changing trend of standard deviations is identical to the axial displacements. When the loading rate is $1 \mathrm{~mm} / \mathrm{min}$, the axial strain values at the three monitoring points of the test samples are the smallest, and their standard deviation is also the smallest, followed by the load of $0.5 \mathrm{~mm} / \mathrm{min}$, the standard deviation difference between the two loading rates $(0.5$ and $1 \mathrm{~mm} / \mathrm{min})$ is rather smaller. This shows that under the loading rates of $0.5 \sim 1 \mathrm{~mm} / \mathrm{min}$, the strain concentration of the tested samples is smaller and the overall distribution of the axial strain is relatively uniform. In practice uniform deformation is a more desired state for assessing UCS reliably. From the observations of the whole axial displacement, the axial strain, and the calculated standard deviations at the three monitoring points in this research, loading rates around $0.5 \sim 1 \mathrm{~mm} / \mathrm{min}$ can be recommended for the UCS tests of the CPB sample.

\subsection{The micro-structural characteristic of the CPB samples}

To better understand the mechanical properties of CPB samples under different loading rates, the micro-structure analysis of the broken samples after the UCS tests were performed using SEM-EDS equipment. It should be noted that all the microstructure information comes from the fracture surface of the tested CPB samples. Fig. 10 shows the SEM morphology of the $\mathrm{CPB}$ fracture surface. It can be seen that the $\mathrm{CPB}$ fracture surface exhibits an obvious porous structure. In addition to the solid particles on the fracture surface, there are also air bubbles and voids between the solid particles. Due to the porous structure of CPB samples, the different SCZs are caused by different loading rates, which affects the UCS. Also, the non-uniform deformation of the $\mathrm{CPB}$ can be caused by the porous structure during the loading process.

\section{(a)}

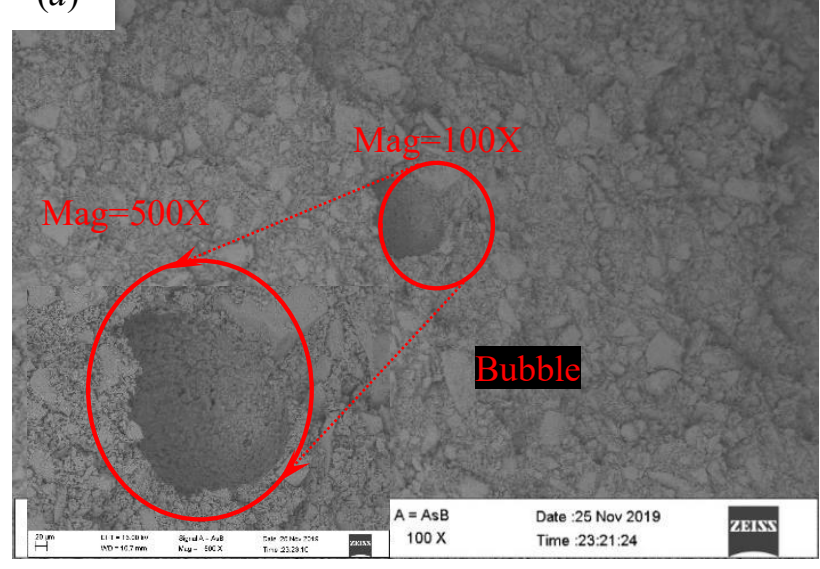

(b)

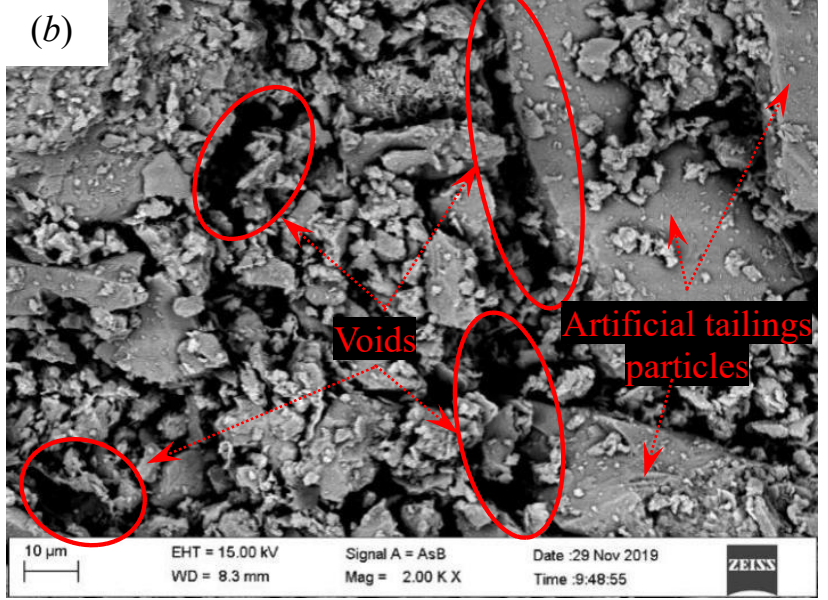

Fig.10 The SEM micrograph of CPB fracture surface: $(a)$ the pore structure; $(b)$ the distribution of voids 
Also, the hydration products of cement in the CPB samples can be clearly seen using SEM method. The hydration products produced by the hydration reaction are the direct source of the UCS for the CPB samples. Fig. 11 shows the distribution of hydration products on the CPB fracture surface after UCS tests. It can be seen that the hydration products mainly include CS-H (calcium-silicate-hydrate) gel and C-H (calcium hydroxide). These two kinds of hydration products are widely distributed on the surface of artificial tailings and in the voids between the artificial tailings particles. These hydration products can not only improve the bonding strength between the particles, but also fill the gaps between the particles.
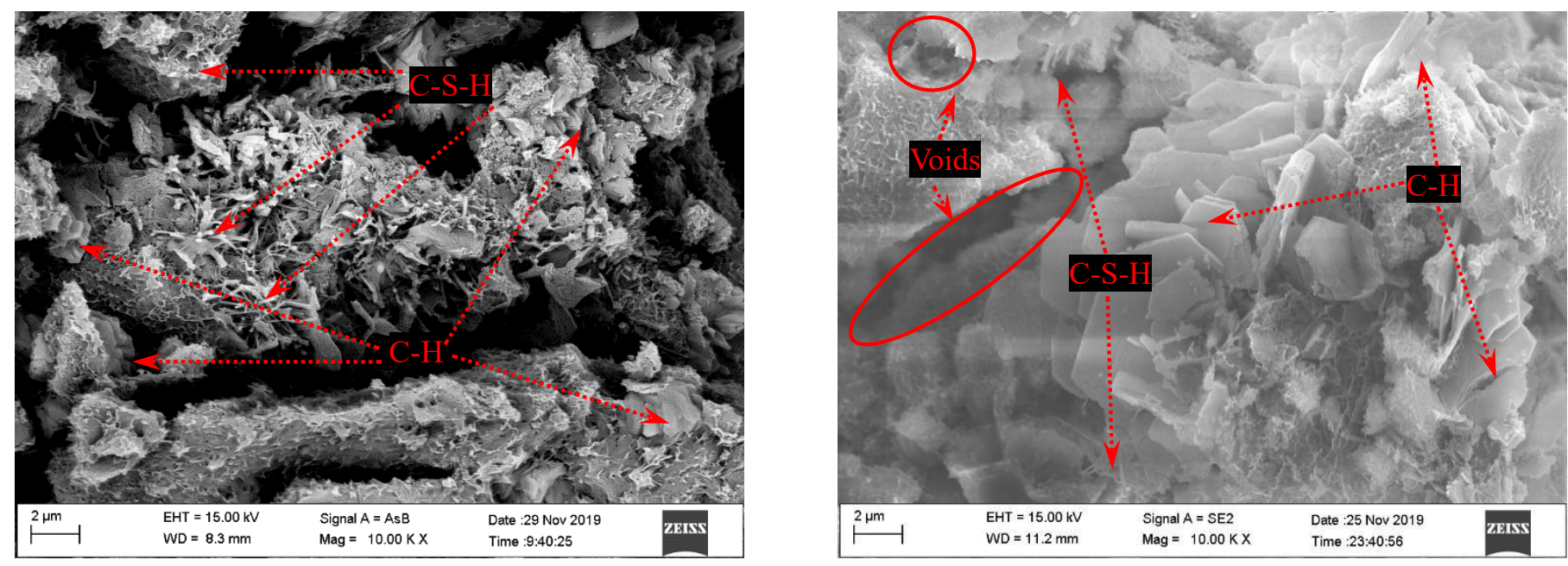

Fig. 11 Distribution of hydration products on the CPB fracture surface after UCS test

During the UCS tests, the failure of the CPB samples were caused by the micro-voids inside the samples being connected to each other under the loading force. Also, the SCZ can be formed by the expansion and connection of micro-voids. The DIC testing results show that the changing process of the SCZ is different under different loading rates. The hydration products around the micro-defects (or micro-voids) are less than the areas where the solid particles are closely connected. When the loading rate is various, the fracture surface for the tested CPB samples should be different from one another. In other words, the content of hydration products on the fracture surfaces maybe different due to the different failure modes.

The tested CPB samples in this study are composed of artificial tailings, tap water, and binder (P.O. 42.5). The artificial tailings are silica sand $\left(99.8 \%, \mathrm{SiO}_{2}\right)$, and the chemical composition of the artificial tailings is shown in the Table1. Cement is a binder material, among which $\mathrm{CaO}, \mathrm{SiO}_{2}, \mathrm{Al}_{2} \mathrm{O}_{3}$ are the main oxides that contribute to the hydration action. The amount of hydration products produced by the hydration reaction play a crucial role for the mechanical behavior of $\mathrm{CPB}$. There are many microdefects (e.g. micro-pores, micro-cracks and bubbles, etc.. As shown in Figs. 10 and 11.). The hydration products around the micro-defects are less than the areas where the solid particles are closely connected. Therefore, the effects of loading rate on the UCS of CPB samples can be explained from a micro perspective by counting the content of hydration products on the fracture surface under different loading rates after UCS tests.

The parameter $\mathrm{Ca} / \mathrm{Si}$ is widely used in the characterization of hydration products. Therefore, the $\mathrm{Ca} / \mathrm{Si}$ of the fracture surface after UCS tests were measured in this study to assess the impacts of different loading rates. To obtain the $\mathrm{Ca} / \mathrm{Si}$ parameter on 
the fracture surface, an appropriate analysis area should be firstly selected on the SEM image (as shown in Fig. 12a). Then, the EDS analysis on the selected area was performed (as shown in Fig. 12b). Also, we can clearly find the distributions of Si and $\mathrm{Ca}$ elements using Figs. 12c and 12d. The Ca/Si parameter can then be finally calculated based on the SEM-EDS testing results. The above-mentioned analysis processes are applied to the statistics of $\mathrm{Ca} / \mathrm{Si}$ parameter on the $\mathrm{CPB}$ fracture surfaces under different loading rates.

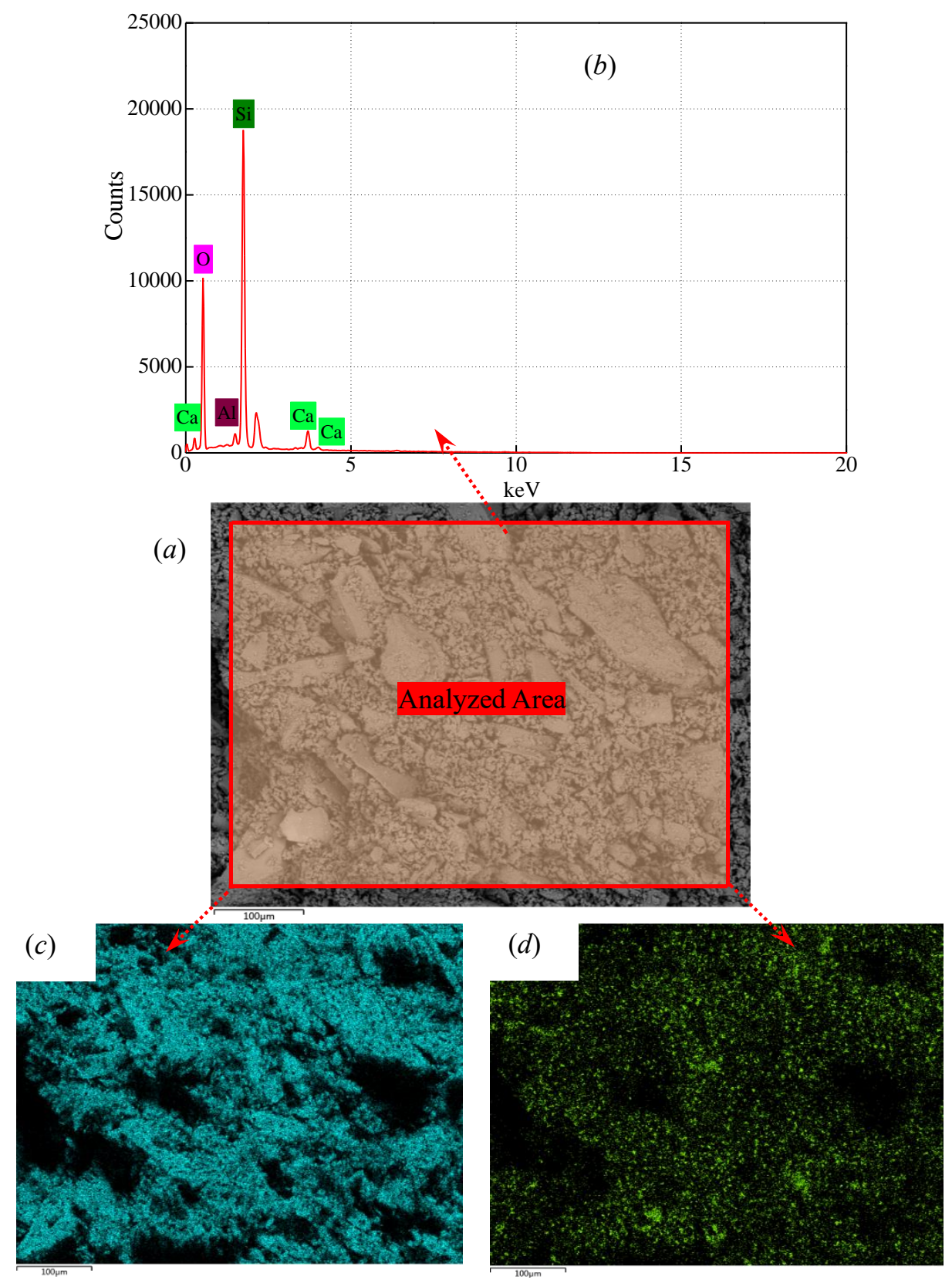

Fig. 12 Statistical analysis of Si and $\mathrm{Ca}$ elements on the fracture surface of CPB samples under the loading rate of 0.1

mm/min: (a) the analyzed area on SEM image; $(b)$ the EDS analysis of analyzed area; $(c)$ distribution of the Si element; $(d)$ distribution of the Ca element

The results of EDS analysis on the fracture surface of tested CPB samples subjected to different loading rates were shown in Table 9. It can be seen that the main elements on the surface are $\mathrm{O}, \mathrm{Si}, \mathrm{Ca}$, and $\mathrm{Al}$. And with the increase of loading rate (from $0.1 \mathrm{~mm} / \mathrm{min}$ to $2 \mathrm{~mm} / \mathrm{min}$ ), the $\mathrm{Ca} / \mathrm{Si}$ parameter on the fracture surface of the tested $\mathrm{CPB}$ samples slightly increased (the 
maximum increase is 0.073 ). This conclusion is consistent with the study of Cao et al. [26].

Table 9 Summary of the EDS analysis on the fracture surface of tested CPB samples subjected to different loading rates.

\begin{tabular}{cccccc}
\hline $\begin{array}{c}\text { Sample } \\
\text { ID }\end{array}$ & $\begin{array}{c}\mathrm{O} \\
\text { (wt.\%) }\end{array}$ & $\begin{array}{c}\mathrm{Si} \\
\text { (wt.\%) }\end{array}$ & $\begin{array}{c}\mathrm{Ca} \\
\text { (wt.\%) }\end{array}$ & $\begin{array}{c}\mathrm{Al} \\
\text { (wt.\%) }\end{array}$ & $\mathrm{Ca} / \mathrm{Si}$ \\
\hline M-14-0.1 & 44.98 & 31.97 & 3.74 & 1.06 & 0.117 \\
$\mathrm{M}-14-0.25$ & 54.64 & 38.36 & 5.43 & 1.57 & 0.142 \\
M-14-0.5 & 50.21 & 41.72 & 6.48 & 1.58 & 0.155 \\
M-14-1 & 51.36 & 40.85 & 6.47 & 1.32 & 0.158 \\
M-14-2 & 48.52 & 35.64 & 6.76 & 1.66 & 0.190 \\
\hline
\end{tabular}

When the loading rate is small, the accumulated energy caused by the loading force can be fully released along the weak bonding surfaces. And the weak bonding surfaces were formed by the connected micro-voids inside of the samples. That is, the tested CPB sample is broken by the connected micro-voids (the weak bonding surfaces) inside of the CPB samples. The hydration products (e.g. C-S-H, C-H, etc.) at the weak bonding surface inside the samples are less distributed, therefore, when the loading rate is smaller, the $\mathrm{Ca} / \mathrm{Si}$ parameter of the failure surface is also lower. However, when the loading rate is higher, the accumulated energy increases sharply at the local position of the tested sample under the loading force. The accumulated energy was suddenly released at which point the tested sample was destroyed without effective transmission and diffusion of the accumulated energy. That is, the CPB sample does not break along with the weak surfaces, when the energy is suddenly released. Therefore, at higher loading rate, the hydration products on the failure surface of the CPB sample are more than that at lower loading rate, and the corresponding $\mathrm{Ca} / \mathrm{Si}$ parameter also is larger than that at lower loading rate.

\section{Discussion}

Under different loading rates, the failure surfaces of test samples show clear variations with different test materials (e.g. rock, concrete, etc.). These different failure surfaces are directly related to the measured strength (e.g. UCS, tensile strength, etc.). Various failure surfaces are often caused by the different responses of micro-defects within the materials to the different loading rates. For material such as rock, the roughness of the fracture surface at a lower loading rate is larger than that at a higher loading rate $[44,45]$. At a lower loading rate, the fracture surface is a connection failure between particles (connection failure). As the loading rate increases, the failure surface develops into a mixed mode (connection failure and particles failure). For rock-like materials or composite materials (e.g. concrete, mortar, etc.), the failure surface occurs at weakly bonded areas under a lower loading rate, while under a higher loading rate the failure surface occurs along both the weakly bonded areas and the aggregates $[46,47]$.

CPB is mainly composed of tailings, water, and binder. The main source of the UCS is the hydration products (e.g. C-H; CH-S gel, etc.) produced during the hydration process, which can connect the solid particles together. However, the inside of the CPB sample is not always homogeneous, and there are many micro-defects (e.g. micro-pores, micro-cracks and bubbles, etc., as shown in Figs. 10 and 11.). The hydration products around the micro-defects are less than the areas where the solid particles are closely connected. When the loading rates vary, the content of hydration products on the fracture surfaces can be 
different due to the different failure modes. In this study, the experimental results showed that as the loading rate increased, the $\mathrm{Ca} / \mathrm{Si}$ parameter on the fracture surface also increased slightly. This observation is consistent with the study of Cao et al. [26]. It is also worth to note, the experimental results discussed in this study are based on the SEM-EDS tests. The SEM-EDS tests focus on a small area of the failure surface and the observed statistics (table 9) are based on the small examined area rather than the entirety of the fracture surface. This may potentially raise concerns on how representative the examined area is. Usually, a random point on each fracture surface was selected to represent the test results (for example, Cao's work, [26]). In this study, the areas with a larger coverage (using the surface scanning method, the scanning area can contain a large number of tailings particles) were used for examining the $\mathrm{Ca} / \mathrm{Si}$ parameter. The statistical results (table 9) can reflect the true state of the fracture surface to a some extent. Further research would be needed when the influences of the area selections on the failure surface for the SEM-EDS tests are to be examined.

\section{Summary and conclusions}

The mechanical behavior of CPB structure has great influence on the stability of the underground mined-out areas. A better understanding on such behavior has its practical importance. UCS is one of the most important indicators of CPB mechanical behavior. To better evaluate the effects of loading rates on UCS of CPB structure, in this study, tests on UCS were performed on 14-day cured CPB samples subjected to various loading rates of $0.1,0.25,0.5,1$, and $2 \mathrm{~mm} / \mathrm{min}$. The DIC method was also used during the testing process. And the SEM-EDS analysis of the CPB samples after UCS tests were carried out to evaluate the micro-structure of the CPB under different loading rates. From the analysis of this research, the following conclusions are drawn:

- The increase of loading rate has a strengthening effect on the UCS behavior of the CPB samples. When the loading rate was increased from 0.1 to $2 \mathrm{~mm} / \mathrm{min}$, the UCS increased by $32.11 \%$. And the correlation between the loading rates and the UCS is more in line with an exponential function.

- The DIC testing results show that the axial deformations of the CPB samples are turned from non-uniform to uniform during the loading process. The distribution and development of the axial SCZ are different under various loading rates. However, regardless of the change in the loading rate, the axial displacements of the tested samples are always showing the same behavior: top (point $\left.1^{\#}\right)>$ middle (point $\left.2^{\#}\right)>$ bottom (point $\left.3^{\#}\right)$.

- When the loading rate is $1 \mathrm{~mm} / \mathrm{min}$, and followed by $0.5 \mathrm{~mm} / \mathrm{min}$, the analysis of standard deviation shows that both the dispersion of the axial displacement and the axial strain at the USC are the smallest. Therefore, $0.5 \sim 1 \mathrm{~mm} / \mathrm{min}$ is recommended as the preferred loading rate for laboratory tests in assessing UCS of CPB sample.

- The SEM-EDS analysis results on the fracture surface of the tested CPB samples show that the axial SCZ generated during the loading process is caused by the interconnected micro-voids inside of the CPB. And as the loading rate is increased, the $\mathrm{Ca} / \mathrm{Si}$ parameter on the fracture surface is also increased slightly. 
This paper has clearly demonstrated that the loading rate has a vital effect on the UCS behavior. It is hoped that the findings in this study may serve as a guidance in selecting appropriate loading rate for the laboratory based assessments of UCS for various $\mathrm{CPB}$ sample.

\section{Declaration of Competing Interest}

The authors declare that they have no known competing financial interests or personal relationships that could have appeared to influence the work reported in this paper.

\section{Acknowledgments}

This work was conducted with supports from the National Natural Science Foundation of China (Grant Nos. U1602232 and 51474050), the Fundamental Research Funds for the Central Universities (Grant No. N17010829), Doctoral Scientific Research Foundation of Liaoning Province (Grant No. 20170540304 and 20170520341). Liaoning Science and Technology Project (2019JH2/10100035), Also, the authors would like to thank PhD. Haiqiang Jiang for supplying the silica tailings and tested molds.

\section{References}

[1] T. Belem, M. Benzaazoua, Design and application of underground mine paste backfill technology, Geotech. Geol. Eng. 26 (2) (2008) 147-174.

[2] C. Xiao, H.C. Zheng, X.L. Hou, X.J. Zhang, A stability study of goaf based on mechanical properties degradation of rock caused by rheological and disturbing loads, Int. J. Min. Sci. Technol. 25 (5) (2015) 741-747.

[3] E. Yilmaz, Stope depth effect on field behaviour and performance of cemented paste backfills, Int. J. Min. Reclam. Env. 32 (4) (2018) 273-296.

[4] W. Li, P. Ni, Y. Yi, Comparison of reactive magnesia, quick lime, and ordinary Portland cement for stabilization/solidification of heavy metal-contaminated soils. Sci. Total. Environ. 671 (2019) 741-753.

[5] S. Cao, W.D. Song, Effect of filling interval time on the mechanical strength and ultrasonic properties of cemented coarse tailing backfill. Int. J. Mineral. Process. 166 (2017) 62-68.

[6] K. Fang, M. Fall, Effects of curing temperature on shear behaviour of cemented paste backfillrock interface, Int. J. Rock Mech. Min. 112 (2018) 184-192.

[7] M. Benzaazoua, P. Marion, I. Picquet, B. Bussière, The use of pastefill as a solidification and stabilization process for the control of acid mine drainage, Miner. Eng. 17 (2) (2004) 233-243.

[8] M. Fall, M. Pokharel, Coupled effects of sulphate and temperature on the strength development of cemented tailings backfills: Portland cement-paste backfill, Cement. Concrete Comp. 32 (10) (2010) 819-828.

[9] Q.S. Chen, Q.L. Zhang, A. Fourie, C. Xin, Utilization of phosphogypsum and phosphate tailings for cemented paste 
backfill, J. Environ. Manage. 201 (2017) 19-27.

[10] M. Fall, D. Adrien, J.C. Célestin, M. Pokharel, M. Touré, Saturated hydraulic conductivity of cemented paste backfill, Miner. Eng. 22 (15) (2009) 1307-1307.

[11] E. Yilmaz, M. Benzaazoua, T. Belem, B. Bussière, Effect of curing under pressure on compressive strength development of cemented paste backfill, Miner. Eng. 22 (9) (2009) 772-785.

[12] O. Nasir, M. Fall, Shear behaviour of cemented pastefill-rock interfaces, Eng. Geol. 101 (3) (2008) 146-153.

[13] R.J. Mitchell, Model studies on the stability of confined fills, Can. Geotech. J. 26 (2) (1986) 210-216.

[14] P.R. Thomson, R.C.K. Wong, Specimen nonuniformities in water-pluviated and moist-tamped sands under undrained triaxial compression and extension, Can. Geotech. J. 45 (7) (2008) 939-956.

[15] E. Yilmaz, T. Belem, M. Benzaazoua, Specimen size effect on strength of cemented paste backfill subjected to different placement condition, Eng. Geol. 185 (2015) 52-62.

[16] Y. Li, L. Jin, L. Zhang, Long-term strengthening effect of cemented tailings considering the loading rates, Electron. J. Geotech. Eng. 21 (3) (2016) 955-968.

[17] Y. Luo, M. Yang, P. Ni, X. Peng, X. Yuan, Degradation of rammed earth under wind-driven rain: the case of Fujian Tulou, China, Constr. Build. Mater. 261 (2020) 119989.

[18] C.X. Liang, X. Li, S.D. Li, J.M. He, C.F. Ma, Study of strain rates threshold value between static loading and quasidynamic loading of rock, Rock Mech. Eng. 31 (6) (2012) 1156-1161.

[19] A.L. Rosa, R.C. Yu, G. Ruiz, L. Saucedo, J.L.A. Sousa, A loading rate dependent cohesive model for concrete fracture, Eng. Fract. Mech. 82 (2015) 195-208.

[20] S. Wisetsaen, C. Walsri, K. Fuenkajorn, Effects of loading rate and temperature on tensile strength and deformation of rock salt, Int. J. Rock Mech. Min. Sci. 73 (2015) 10-14.

[21] E. Panteki, P. Máca, U. Häussler-Combe, Finite element parametric study on the effect of loading rate on the bond of reinforcement in concrete, Procedia Eng. 210 (2017) 39-44.

[22] W. Yao, K.W Xia, Y.H. Liu, Y.R. Shi, K. Peterson, Dependences of dynamic compressive and tensile strengths of four alkali-activated mortars on the loading rate and curing time, Constr. Build. Mater. 202 (2019) 891-903.

[23] X. Chen, X. Shi, J. Zhou, Q. Chen, E. Li, X. Du, Compressive behavior and microstructural properties of tailings polypropylene fibre-reinforced cemented paste backfill, Constr. Build. Mater. 190 (2018) 211-221.

[24] H.Q. Jiang, M. Fall, Y.H. Li, J. Han, An experimental study on compressive behaviour of cemented rockfill, Constr. Build. Mater. 147 (2019) 837-846.

[25] M. Fall, M. Pokharel, Coupled effects of sulphate and temperature on the strength development of cemented tailings backfills: Portland cement-paste backfill, Cement Concrete Comp. 32 (10) (2010) 819-828. 
[26] S. Cao, E. Yilmaz, W.D. Song, E. Yilmaz, G.L. Xue, Loading rate effect on uniaxial compressive strength behavior and acoustic emission properties of cemented tailings backfill, Constr. Build. Mater. 213 (2019) 313-324.

[27] Y. Li, L. Jin, L. Zhang, Long-term strengthening effect of cemented tailings considering the loading rates, Electron. J. Geotech. Eng. 21 (3) (2016) 955-968.

[28] S. Huang, K.W. Xia, L. Qiao, Dynamic tests of cemented paste backfill: effects of strain rate, curing time, and cement content on compressive strength, J. Mater. Sci. 46 (15) (2011) 5165-5170.

[29] X.R. Liu, K. Liu, K. Zhao, J.T. Hu, Strain rate effects and acoustic emission characteristics of tailing cement backfill under uniaxial compression, Electron. J. Geotech. Eng. 18 (1) (2013) 3919-3932.

[30] L. Orejarena, M. Fall, The use of artificial neural networks to predict the effect of sulphate attack on the strength of cemented paste backfill, Bull. Eng. Geol. Environ. 69 (4) (2010) 659-670.

[31] W.C. Li, M. Fall, Sulphate effect on the early age strength and self-desiccation of cemented paste backfill, Constr. Build. Mater. 106 (2016) 296-604.

[32] K. Fang, M. Fall, Chemically induced changes in the shear behaviour of interface between rock and tailings backfill undergoing cementation, Rock Mech. Rock. Eng. 52 (9) (2019) 3047-3062.

[33] M. Fall, O. Nasir, Mechanical behaviour of the interface between cemented tailings backfill and retaining structures under shear loads, Geotech. Geol. Eng. 28 (6) (2010) 779-790.

[34] K. Fang, M. Fall, Effects of curing temperature on shear behaviour of cemented paste backfillrock interface, Int. J. Rock Mech. Min. 112 (2018) 184-192.

[35] D.A. Landriault, Paste fill at Inco. In: Proceedings of the 5th International Symposium on Mining with Backfill, Johannesburg: South Africa, (1992) 8.

[36] ASTM D2487-17e1, Standard Practice for Classification of Soils for Engineering Purposes (Unified Soil Classification System), ASTM International, West Conshohocken, PA, 2017.

[37] O. Peyronnard, M. Benzaazoua, Alternative by-product based binders for cemented mine backfill: Recipes optimisation using Taguchi method, Miner. Eng. 29 (2012) 28-38.

[38] ASTM C143/C143M-15 Standard Test Method for Slump of Hydraulic-Cement Concrete, ASTM International, West Conshohocken, PA, 2015.

[39] P.A. Reu, Study of the influence of calibration uncertainty on the global uncertainty for digital image correlation using a Monte Carlo approach, Exp. Mech. 53 (9) (2013) 1661-1680.

[40] Y. Zhou, C. Sun, J. Chen, Adaptive subset offset for systematic error reduction in incremental digital image correlation, Opt. Lasers Eng. 55 (2014) 5-11.

[41] X. Shao, X. Dai, Z. Chen, X. He, Real-time 3D digital image correlation method and its application in human pulse 
monitoring, Appl. Opt. 55 (2016) 696-704.

[42] Z. Hu, H. Xie, J. Lu, H. Wang, J. Zhu, Error evaluation technique for three-dimensional digital image correlation, Appl. Opt. 50 (33) (2011) 6239-6247.

[43] N.R. Kolanu, P.S. Suriya, M. Ramji, Experimental study on compressive behavior of gfrp stiffened panels using digital image correlation, Ocean Eng. 114 (2016) 290-302.

[44] Q.B. Zhang, J. Zhao, Effect of loading rate on fracture toughness and failure micromechanisms in marble, Eng. Fract. Mech. 102 (2013) 288-309.

[45] M. Ju, J. Li, X. Li, J. Zhao, Fracture surface morphology of brittle geomaterials influenced by loading rate and grain size, Int. J. Impact. Eng. 133 (2019) 103363.

[46] J. Wu, X. Liu, H. Wu, L. Li, Z. Liu, Dynamic Compressive Behavior of Asphalt Concrete Material under Impact Load, J. Test. Eval. 4 (48) (2020) 2768-2785.

[47] E.Z. Lajtai, E.J.S. Duncan, B.J. Carter, Effect of Strain Rate on the Compressive Strength Surface. ACI Mater. J. 24 (1991) 99-109. 


\section{Figure Captions}

Fig. 1 The artificial tailings used in this study: (a) the artificial tailings used in this study; (b) the scanning electron microscope (SEM) image (magnified 500 times); (c) the main elements of the artificial tailings

Fig. 2 The particle size distribution curves of the silica tailings and the average of 7 mines tailings

Fig. 3 Experimental set-up for DIC system: $a$. Loading system; $b$. Tested sample; $c$. DIC apparatus; $d$. DIC computer; $e$. Light sources; $f$. Cameras

Fig. 4 The simplified schematic diagram of DIC method

Fig. 5 The region of interest (ROI) of a tested sample

Fig. 6 The Axial stress $v s$. Axial displacement curves under different loading rates

Fig.7 The relationship between UCS and loading rate for tested CPB samples

Fig. 8 The axial displacement and axial stain curves for the given three points of the tested CPB samples: $(a) 0.1 \mathrm{~mm} / \mathrm{min} ;(b)$ $0.25 \mathrm{~mm} / \mathrm{min}$; (c) $0.5 \mathrm{~mm} / \mathrm{min} ;(d) 1 \mathrm{~mm} / \mathrm{min} ;(e) 2 \mathrm{~mm} / \mathrm{min}$

Fig. 9 The standard deviations of displacement and axial strain at the USC under different loading rates: $(a)$ axial displacement; (b) axial strain

Fig.10 The SEM micrograph of CPB fracture surface: $(a)$ the pore structure; $(b)$ the distribution of voids

Fig. 11 Distribution of hydration products on the CPB fracture surface after UCS test

Fig. 12 Statistical analysis of $\mathrm{Si}$ and $\mathrm{Ca}$ elements on the fracture surface of CPB samples under the loading rate of $0.1 \mathrm{~mm} / \mathrm{min}$ :

(a) the analyzed area on SEM image; (b) the EDS analysis of analyzed area; (c) distribution of the Si element; $(d)$ distribution of the $\mathrm{Ca}$ element 